\title{
BIOPEDAGOGICAL MODELING OF SPORTS PREPARATION OF VOLLEYBALL PLAYERS OF HIGH QUALIFICATION
}

\author{
Irina Kabulbekova, Ludmila Kudashova, Eugene Kudashov
}

\begin{abstract}
Summary
Introduction. In modern volleyball, the achievement of high sports results is impossible without scientifically based management of preparation of volleyball players of high qualification, it demands creation of models of an object, the different parties of preparedness and preparation, the analysis of dynamics of their development and the forecast of achievements that is possible on the basis of data of bio pedagogical modeling.

Research objective - to define functional prospect of volleyball players of high qualification on the base of an assessment of level of their bio pedagogical models in the competitive period. The methodology of the researches was based on the scientific works of Yu. V. Verkhoshansky, A. I. Zavyalov, D. G. Mindiashvili, and others, linking the maximum training effect with the necessity of rational combination of pedagogical influences and biological control.

Results of a research and their discussion. Were determined the levels of relevant models of functional capabilities of volleyball players of team of higher League of Kazakhstan in the competitive period. A low assessment is given to physiological reserves of the organism, which influence on the technical actions of athletes, that requires systematic correction by bio pedagogical means.

Conclusions:

1. The average level of relevant models of physical working capacity at a pulse of 150 beats/min and 170 beats/min of volleyball players at the beginning of the competitive period has decreased to low values, that speaks about the low energy capacity of reserves of an organism.

2. Decrease of level of the general physical working capacity was followed by a decrease of efficiency of performance of technical and tactical elements, which speaks about low energy reserves.
\end{abstract}

Introduction. Achievement of high sports results in modern volleyball is impossible without scientific-well founded management of the preparation of volleyball players of high qualification, which should be based on modern theoretical and practical technologies in pedagogy and biology. It demands in sports science not of mechanical transfer of the stereotypical standard approaches and paradigms, which have developed five decades ago, but revision of all system of complex preparation. The coach should possess science-based information and techniques of management of the hidden biological reserves of the person, that are retained at the biological cellular level and the solution of tasks of their correction associated with the achievements of biopedagogics of sport and its introduction in preparation of coaches.

Absence of single conceptual approaches in regard to biopedagogics and her actual base of functional preparation with technology of her realization in a training process constrains scientifically-based process of management of sports preparation of athletes in general, and volleyball players in particular.
Characteristic features of modern conditions of the development of sport is the use in the training process of large volumes near maximum physical loads without regard the biological adaptive abilities of the organism. This puts the athlete's organism on the verge of overstrain and exhaustion, as a result is absent growth of reserve opportunities of organism and are shown not high sport results. All of this is the consequence connected with conservatism and insufficient creativity of thinking of many scientists and coaches adhering to old conceptions in preparation of athletes of high qualification and difficult perceiving innovative approaches in sport that affects not only effectiveness, but also physical health of athletes.

In this connection appears the necessity of more wide introduction to the theory and practice of sport of the long ago proposed direction in sport science, but not yet found wide implementation, it is science - biopedagogics of sport, the aim of which - rationally combine pedagogical and sporting orientations with biological reactions for the receipt of maximal training effect without violation of health of the athlete. 
The biopedagogics of the sport as the scientific direction opens in the person additional opportunities and reserves, putting the healthy person in extreme conditions of sport, which in usual state is remained unsolved. The hidden reserves need to be open and used for deeper studying of regularities of formation of sports skill depending on the level of functional athlete's possibilities, and also factors influencing their interrelations. The medicine is busy with problems of recovery of health of the sick person to norm.

In base of the science the bio pedagogics of sport lie the problems of theoretical and practical bases about regularities of action and interaction of various training routines in programs of occupations, their biological mechanisms and opportunities to operate organism reserves at the level of the cells of organs and the systems of organism at the formation of training for maintenance a high level of work capability.

From the point of view of biopedagogics of sport, sports preparation - is a scientifically-based pedagogical process of the purposeful formation of means of physical culture and sport, biological morphological structures of cells of organs and tissues of man by means of physical culture and sports that promote the accumulation of reserves of bioenergetics potential and more effective manifestation of physical qualities and technical-tactical actions. Without knowledge of the above features, the training process and sports work capacity of a person in conditions of muscular activity is based on amateurish and incompetent approach, which leads to overtraining of the organism or to the lack of the desired training effect, injuries and occupational diseases in the physical culture and sports.

At the modern stage of the scientific substantiation of the development of sport, it is necessary to emphasize the attention of coaches and teachers of physical culture, that the training of athletes should be based on a new direction of science of biopedagogics with inclusion in it of biological laws of management. Sport is the management of the biological object of the human organism at the cellular, organ and systemic levels, therefore the management of its sports opportunities and abilities has to be based on bio-pedagogical knowledges.

To a great extent, is reveals the actuality of the process of considering a holistic theory and practice of sport and the biology of sport. It is necessary to emphasize that the sports science, is, first, science about management of physical capabilities and human health on the basis of scientific substantiation of the theoretical, methodical and practical bases of formation the morpho-functional reserves of organism taking into account current trends of development of sport. Models of separate training routines and their complexes should be formed on the basis of taking into account the mechanisms of urgent adaptation and optimality of impacts at the longer exposures of pedagogical means, for the more purposeful improvement of various parameters of long effects of preparedness. Models of training loads, duration of separate exercises and their complexes, intensity of work, duration and character of pauses between exercises, determination of total number of exercises have to be selected taking into account the physiological, biochemical and bioenergetics reactions of the organism.

Comparison of individual characteristics of the competitive activity with the model data allows establishing the most general reserves of increasing the level of the athlete's preparedness, to determine the bioenergetics value of the applied loads and the effectiveness of using pedagogical means at preparation of the athletes.

The analysis of literature shows that coaches belong without the due understanding to the management by functional preparedness of athletes of its importance that requires actualization of this problem of bio pedagogical approaches and practical introduction in the training activity. It is necessary to prove need of inclusion of functional preparation and control of preparedness of athletes in the structure of sports preparation, as the important factors, limiting sporting achievements. Ignoring in training process of assessment of efficiency of functional preparation and the state of physiological readiness of organism often leads to breakdown of mechanisms of adaptation of organism and decrease of the sports results. Functional training it is a planned, multifactorial process of management of the individual biological reserves of the human organism with use of various pedagogical means and methods of physical, technical, tactical and mental training. The purpose of functional preparation in sport is expansion of borders of the functional adaptation, allowing without loss to health to transfer the increased volumes of training and competitive loads, reaching at the same time great sports 
workmanship [L. Kudashova, 1]. The scientifically grounded management of preparation of volleyball players of high qualification supposes creation of models of the object and analysis of tendencies of its development, the forecast on the basis of modeling is a necessary component of any training process.

Actually fits into the biopedagogics of sport in our opinion sports and pedagogical adaptology (methodical achievements) proposed by V. Seluyanov [2]. According to his opinion, one of the main tasks of pedagogy is the development of new means and methods of education, taking into account their biological impacts. Instrument for the development of new pedagogical methods is the imitation simulation with the use of speculative or computer models of organism of man. With the help of imitation simulation, the most effective variants of performing physical exercises that solve the set aim are identified. Theoretical and imitation modeling with the definition of qualitative and quantitative impact assists prediction of modification in cells of tissues of athletes. Efficiency of biological modeling and the forecast has to be proved in researches in practice.

Taking into account the above, in the present scientific researches the following aim has been set: to determine the functional prospect of volleyball players of high qualification based on an assessment of the level of their bio pedagogical models in the competition period.

The methodology of the research was based on scientific works of Yu.V. Verkhoshansky [3, 4], V.N. Seluyanov [2], A.I. Zavyalov, D. G. Mindiashvili [5], L. R. Kudashova [1], and others, linking the maximum training effect with the necessity of rational combination of pedagogical influences and bio pedagogical control for more effective management of sports preparation. Not possession by coach of knowledges about influence of exercise stresses on the functional biological structures of organism, lies in the base of manifestation of physical working capacity do not allow scientifically-based to operate sports preparation.
Organization of research. Researches were conducted in the competitive period of the RK Championship on 13 volleyball players of women's club team of the highest league, at the age of 15-20 years. The competition period for volleyball players of the highest league lasts from November to April, and includes 5 rounds. We conducted research in the period of 2, 3 and 4 rounds of the RK Championship a week before the start of the next round, which took place in different cities of the Republic of Kazakhstan (Almaty, Pavlodar, Temirtau).

The analysis of relevant models of physical working capacity and the maximum consumption of oxygen of volleyball players of high qualification before the beginning the second and third round with assessment of their possible influence on results of competitive tours of Republican value is carried out.

\section{Results of research and their analysis.}

The level of physical working capacity (the value of $P W C 1_{70}$, by us was used as a method of objective assessment of the functional state and training of athletes. $\mathrm{PWCl}_{70},-$ corresponds to the first letters of the English term Physical Working Capacity (physical working capacity) and corresponds to that power of external mechanical work $(\mathrm{kg} / \mathrm{min})$, which results in the heart rate increasing to 170 beats per minute. The $\mathrm{PWC1}_{70}$ level is connected with such important indicators as volume of a heart, quantity of hemoglobin, energy reserves of muscle cells, quantity of mitochondrions in the myofibrils, the maximum consumption of oxygen (MCO). To calculate the $\mathrm{PWC1}_{70}$ and the MPC used the test of Karpman V.S. with co-authors [6]:.

$\mathrm{PWC1}_{70}$ - physical working capacity at pulse of 170 beats/min; $\mathrm{W}_{2}$ - power of the second load; $\mathrm{f}_{1}$ - pulse after first load; $f_{2}-$ pulse after second load. Calculation of the MPC was carried out according to the formula of V.L. Karpman with co-authors. [6], $\mathrm{MPC}=2.2 * \mathrm{PWC}_{170}+1070$. The relative values of indicators of the PWC, calculated per kilogram of weight, were determined at a pulse of 130,150, 170 beats/min and MPC and were estimated at zones proposed by A. G. Zima and co-authors [6], Table 1. 
Table 1 - Estimated zones of physical working capacity of a person in relative values at a different pulse rate at the women (A.G. Zima with co-authors, 1985).

\begin{tabular}{|c|c|c|c|c|c|c|}
\hline \multirow[t]{2}{*}{$\begin{array}{l}\text { Zone name } \\
\text { PWC }\end{array}$} & \multicolumn{5}{|c|}{$\begin{array}{l}\mathrm{PWC}, \mathrm{kg} / \mathrm{min} / \mathrm{kg} \text {, at a heart rate per } \\
\text { minute }\end{array}$} & \multirow{2}{*}{$\mathrm{MPC}, \mathrm{ml} \cdot \mathrm{min}^{-1} \cdot \mathrm{kg}^{-1}$} \\
\hline & 130 & 150 & 170 & 180 & $\max$ & \\
\hline & \multicolumn{6}{|c|}{ For women } \\
\hline Very high & 12 & 16,7 & 22 & 25 & 29 & 63,4 \\
\hline Excellent & 9,9 & 14,3 & 19 & 21,5 & 25 & 55,3 \\
\hline Good & 8,5 & 12,3 & 14,5 & 16,3 & 18,5 & Higher 43,3 \\
\hline Average & 7,3 & 10,7 & 14,5 & 16,3 & 18,5 & 43,3 \\
\hline $\begin{array}{l}\text { Reduced, } \\
\text { below average }\end{array}$ & $\begin{array}{l}\text { B e - } \\
\text { low } \\
7,3\end{array}$ & $\begin{array}{l}\text { B e - } \\
\text { low } \\
10,7\end{array}$ & $\begin{array}{l}\text { Below } \\
14,5\end{array}$ & $\begin{array}{l}\text { B e - } \\
\text { low } \\
16,3\end{array}$ & $\begin{array}{l}\text { B e - } \\
\text { low } \\
18,5\end{array}$ & $\begin{array}{l}\text { Below } \\
43,3\end{array}$ \\
\hline Low & 6,5 & 9,6 & 13 & 15 & 17 & 39,8 \\
\hline Very low & 6,7 & 8.7 & 11,5 & 13,5 & 15 & 36,6 \\
\hline
\end{tabular}

The indicators of the level of physical working capacity at a pulse of $130,150,170$ beats per minute and the MPC of the volleyball team, in the second round of the competition period are presented in Table 2. The statistics were calculated by the Excel program "Statistics".

\section{Analysis of results of own researches}

In the first series of studies, the analysis of the games of the 2 nd round was conducted, from which was found out that in this round from 5 games all were won, 2 of them with a score of 3:2, 2 games with a score of 3:1 and one with an account 3:0. Results of research of relative values of the general physical working capacity at pulse regime 130,150 and 170 beats $/ \mathrm{min}$ (PWC, $\mathrm{kg} / \mathrm{min} / \mathrm{kg}$ ) and the MPC $(\mathrm{ml} / \mathrm{min} / \mathrm{kg})$ of team of volleyball players of high qualification, are presented in Table 2 . The analysis revealed that prior to the beginning of the competition period of the second round, from $46.3 \%$ to $54 \%$ of athletes had low values of the general physical working capacity at a pulse of $130-170$ beats/min and the ability to consume the maximum quantity of oxygen (MPO) at $61.5 \%$.
Given that the team won all games in this round, but the result in the sets was low, it required to find out, which of the functional indicators studied are influenced in a greater extent on the results of the game. For this, calculations of the correlation coefficient between the number of the lost sets in 5 games of 2 round and the level of the general physical working capacity and the ability of maximum oxygen consumption were performed.

Calculation of coefficient of correlation between the level of the reserves providing the general physical working capacity at different pulse regimes and the maximum opportunities to consume oxygen, has shown that the efficiency of results of sports competitions of Republican importance, in a greater extent, influenced indicators of physical working capacity at a pulse of 150 beats per minute $(r=$ $0,944, p<0.05$ ) (Table 3 ). It is established below the average values the dependence of the effectiveness of the results of sports competitions from the level of $\mathrm{PWC}_{170}$ and MPC and very weak from $\mathrm{PWC}_{130}$. These features, obviously, are connected with the fact that up to $44 \%$ of athletes had low profitability of physiological reserves and MPC levels. 
Table 2 - Percent of the volleyball players of high qualification having functional indicators in different zones of physical working capacity at the beginning of the 2 nd round of the championship of the Republic of Kazakhstan.

\begin{tabular}{|l|l|l|l|l|}
\hline $\begin{array}{l}\text { Zone } \\
\text { assessment PWC, }\end{array}$ & $\mathrm{PWC}_{170,} \mathrm{~kg} / \mathrm{min} / \mathrm{kg}$ & $\mathrm{PWC}_{150,} \mathrm{~kg} / \mathrm{min} / \mathrm{kg}$ & $\mathrm{PWC}_{130,} \mathrm{~kg} / \mathrm{min} / \mathrm{kg}$ & $\begin{array}{l}\mathrm{MPC}, \\
\mathrm{ml} / \mathrm{min} / \mathrm{kg}\end{array}$ \\
\hline & \multicolumn{5}{|l|}{} \\
\hline High & Percent of the volleyball players in zones & 7,6 \\
\hline Good & 15,4 & 15,4 & 23 & 7,6 \\
\hline Average & 0 & 7,6 & 23 & 23 \\
\hline Low & 38,5 & 23 & 7,6 & 46,1 \\
\hline Very low & 30,7 & 23 & 15,4 & 15,4 \\
\hline
\end{tabular}

Table 3 - Coefficient of correlation between the level of physical working capacity at a pulse $130,150,170$ beats/min, maximum oxygen consumption (MPC) and the number of lost sets in the 2nd round of the Championship of the Republic of Kazakhstan.

\begin{tabular}{|l|l|l|l|l|}
\hline $\begin{array}{l}\text { the number of lost sets in } \\
\text { the 2nd round }\end{array}$ & $\mathrm{PWC}_{170,} \mathrm{~kg} / \mathrm{min} / \mathrm{kg}$ & $\mathrm{PWC}_{150,} \mathrm{~kg} / \mathrm{min} / \mathrm{kg}$ & $\mathrm{PWC}_{130,} \mathrm{~kg} / \mathrm{min} / \mathrm{kg}$ & $\begin{array}{l}\mathrm{MPC}, \\
\mathrm{ml} / \mathrm{min} / \mathrm{kg}\end{array}$ \\
\hline $\mathrm{r}_{2-2 \text { nd round }}$ & 0,399 & 0,944 & 0,169 & 0,377 \\
\hline $\mathrm{r}_{3-3 \text { round }}$ & 0,544 & $-0,028$ & $-0,268$ & 0,484 \\
\hline $\mathrm{r}_{4-4 \text { round }}$ & 0,536 & 0,490 & 0,746 & 0,490 \\
\hline
\end{tabular}

High models in zone of aerobic power had less thirds of part of volleyball players of high qualification, namely $15.4 \%$, they worked at high level in the zone mixed (aerobic and anaerobic) capacities and $15.4 \%$ in zone of anaerobic power, i.e. could stay a prolonged physical loads (for example, games from 5 rounds). Insufficient percentage of athletes having high and good physiological reserves of organism had led to loss up to $40 \%$ of points in technical-tactical activities.

Table 4 - Percent of the volleyball players having functional indicators in different zones of physical working capacity at the beginning of the 3 rd round of the RK championship.

\begin{tabular}{|c|c|c|c|c|}
\hline Zone level PWC & $\mathrm{PWC}_{170}$ & $\mathrm{PWC}_{150}$ & $\mathrm{PWC}_{130}$ & MPC \\
\hline & \multicolumn{4}{|c|}{ Percent of the volleyball players in zones } \\
\hline High & 0 & 0 & 0 & 0 \\
\hline Good & 15,4 & 30,8 & 38,5 & 15,4 \\
\hline Average & 15,4 & 23 & 15,4 & 15,4 \\
\hline Low & 30,7 & 7,7 & 7,6 & 46,2 \\
\hline Very low & 38,5 & 38,5 & 38,5 & 23 \\
\hline
\end{tabular}

In this third round from 5 games the team has won only 2 games (with the score 3-2 and 3-1) and have lost 3 (with the score 2-3, 1-3 and 0-3). The assessment of the correlation coefficient showed (Table 3) that communications of technical-tactical skills with the functional preparedness were in the middle zone with the $\mathrm{PWC1}_{70}$ and MPC indicators, and
According to the results of the study in the middle of championship, to beginning $3 \mathrm{rd}$ round were set, that the average values of $\mathrm{PWC1}_{30,150,170}$ and MPC at all inspected volleyball players decreased to the low zone of physical working capacity, as compared to 2 nd round (Table 4). It should be noted that before the 3rd tour there were no more volleyball players having reserves in high zone of physical working capacity, it says also about the low bioenergetics capacity and lack of its correction between tours and that the coach did not control functional preparedness and did not correct it. were absent with the $\mathrm{PWC1}_{50}$ and ${ }_{130}$ levels. According to the results of the study, at the beginning of the 4th round of the Republican championship, the $\mathrm{PWC}_{130,150,170}$ level was reduced and the MPC compared with the second and third rounds, and besides there were no players with indicators in the high zone of physical working capacity (Table 5). 
Table 5 - Percent of the volleyball players having functional indicators in different zones of physical working capacity at the beginning of the fourth round of the RK championship.

\begin{tabular}{|l|l|l|l|l|}
\hline Zone level PWC & $\mathrm{PWC}_{170}$ & $\mathrm{PWC}_{150}$ & $\mathrm{PWC}_{130}$ & $\mathrm{MPC}$ \\
\hline High & 0 & 0 & 0 & 0 \\
\hline Good & 15.4 & 30.8 & 38.5 & 15.4 \\
\hline Average & 15.4 & 23 & 15.4 & 15.4 \\
\hline Low & 30.7 & 7.7 & 7.6 & 46.2 \\
\hline Very low & 38.5 & 38.5 & 38.5 & 23 \\
\hline
\end{tabular}

The decline of percent of players working in the good zone of physical working capacity was noted.

The analysis of interrelation of technical-tactical skill with functional preparedness in the 4th round of the volleyball championship has shown on growth of dependence to average values with all indicators of $\mathrm{PWC}_{170,150,130}$ and MPC. These changes testify that not taking into consideration of correction of functional preparedness by the coach of bio pedagogical means leads to deterioration of models of physical working capacity of athletes and decrease of levels of the athletes who are in high and good zones of working capacity that has caused instability of game results.

\section{Conclusion}

Analysis in the competitive period of the relevant models of functional capabilities of volleyball players of the club team performing in the higher league of Kazakhstan allowed asserting that the low level of physiological reserves of the organism influences the effectiveness of technical activities of female athletes, which requires systematic correction by bio pedagogical means.

Is established the average level of relevant models of physical working capacity at a pulse of 150 beats/min and 170 beats/min at volleyball players at the beginning of the competitive period, which decreases to low values by the end of round of the championship, that says about low energy capacity of the organism oxygen reserves, low quantity of mitochondrions, providing by the oxygen intense competitive activity.

Decrease of the level of the general physical working capacity is interconnected with falling of efficiency of performance of technical-tactical activities as at the beginning, as and in the end of competitive tour that is explained not high energy reserves of volleyball players and the lack of management by this side of preparation by the coach, that is one of the reasons for the lost sets.

The modern sport of higher achievements demands preparation and retraining of coaches and teachers of physical culture and sport, taking into account development of the scientific direction of biopedagogics of physical culture and sport.

\section{Literature}

Karpman V.L., Belotserkovskiy Z. B., Gudkov I. A. Testing in sports medicine.- Moscow: F\&S, 1988.- P. 197.

Kudashova L.R. Questions of management of functional preparedness of athletes /L.R. Kudashova//Physiology of muscular activity: thesis report of the international conference - M.: Physical culture, education and science.2000.-Page 84-85.

Seluyanov V.N. Empirical and theoretical ways of development of the theory of sports preparation / / Theory and practice of physical culture.- 1998.- No. 3.- P. 4650.

Verkhoshansky Yu. V. Horizons of scientific theory and methodology of sports training. // Theory and practice of physical culture.-1998.- № 7.- P. 41-54.

Verkhoshansky Yu. V. On the way to the scientific theory and methodology of sports training. // Theory and practice of FC.- 1998.- № 2.- P. 21

Zavyalov A.I., Mindiashvili D. G. Biopedagogics or sports training.- Krasnoyarsk. MP "Polis".-1992.- P. 58. 